\title{
UNIFORMIZATION OF FRONTIERS IN NON-RADIAL ZSG-DEA MODELS: AN APPLICATION TO AIRPORT REVENUES
}

\author{
Aline Bandeira de Mello Fonseca \\ Mestrado em Engenharia de Produção \\ Universidade Federal Fluminense (UFF) \\ Niterói - RJ \\ aline.mello@ig.com.br
}

João Carlos Correia Baptista Soares de Mello*

Departamento de Engenharia de Produção

Universidade Federal Fluminense (UFF)

Niterói - RJ

jcsmello@pesquisador.cnpq.br

\section{Eliane Gonçalves Gomes}

Empresa Brasileira de Pesquisa Agropecuária (Embrapa) Brasília - DF

eliane.gomes@embrapa.br

\section{Lidia Angulo Meza}

Departamento de Engenharia de Produção

Universidade Federal Fluminense (UFF)

Volta Redonda - RJ

lidia_a_meza@pq.pnpq.br

* Corresponding author / autor para quem as correspondências devem ser encaminhadas

Recebido em 10/2008; aceito em 07/2009 após 1 revisão Received October 2008; accepted July 2009 after one revision

\begin{abstract}
We propose in this paper an extension to the Zero Sum Gains Data Envelopment Analysis model (ZSG-DEA). The proposed approach takes into account, simultaneously, non-radial projections and cone-ratio weights restrictions. We developed an iterative approximate algorithm to solve this model, as in the case study it is oriented only to the constant sum output. The theoretical approach is applied to the concession of discounts and surcharges problem, in terms of airport fees.
\end{abstract}

Keywords: DEA; zero sum gains; non-radial projections; airport fees.

\section{Resumo}

É proposta neste artigo uma extensão do modelo de Análise de Envoltória de Dados com Ganhos de Soma Zero (DEA-GSZ). Esta extensão considera simultaneamente projeções não radiais e restrições do tipo cone-ratio. Mostra-se necessário para a resolução do modelo proposto, o uso de um algoritmo iterativo aproximado. Isto se deve ao fato de o modelo ser orientado a somente um dos outputs, o de soma constante. $\mathrm{O}$ modelo teórico desenvolvido é exemplificado a um problema de concessão de descontos e sobretaxas em tarifas aeroportuárias.

Palavras-chave: DEA; ganhos de soma zero; projeções não radiais; tarifas aeroportuárias. 


\section{Introduction}

One of the most studied applications for measurements obtained using DEA is the distribution or redistribution of resources. Research in this area has been conducted, for example, by Yan et al. (2002), Beasley (2003), Korhonen \& Syrjänen (2004), Lozano \& Villa (2004, 2005), Soares de Mello et al. (2006), Gomes et al. (2007), Fang \& Zhang (2008), Haidi-Vencheh et al. (2008) and Asmild et al. (2009).

In the past few years, DEA models have been developed following the concept that resources are limited and, therefore, in order to attribute more resources to a DMU one needs to remove them from another. These models seek to obtain a frontier with the maximum number of efficient DMUs (ideally all should be efficient).

One of these models parameterizes a final frontier that is obtained when all DMUs are efficient. Avellar et al. $(2005,2007)$ and Guedes et al. (2009) arbitrated a spherical form for this frontier. The Spherical Frontier DEA Model, as it is called, deals with the distribution of both new and existing resources.

Another class of models solve problems of the same type without the need to choose a function for the frontier. This type of model was primarily applied in cases where the production of the DMUs was not independent. It was first developed to establish Olympic medal goals at the Sydney Olympic Games (Lins et al., 2003) and is named Zero Sum Gains DEA model (ZSG-DEA). Initially, the condition for zero sum gains was only applied to the DEA BCC model, proposed by Banker et al. (1984).

Gomes et al. (2003) have adapted the ZSG-DEA model to the uniformization of the frontier with a redistribution of outputs. For this they have used a modelling of iso-efficiency layers (Barr et al., 2000; Gomes et al., 2009b). Gomes et al. (2004) used the ZSG-DEA model for a redistribution of outputs and inputs with the uniformization of the frontier in a different way: instead of reducing the production and preserving the resources of initially efficient DMUs, they forced them to diminish outputs as well as reduce inputs. In order to solve the mathematical problem of determining one equation for each facet of the frontier, they used the smoothed frontier developed by Soares de Mello et al. $(2002,2004)$ and Nacif et al. (2009).

Gomes et al. (2005) extended the use of ZGS-DEA models to constant returns to scale (Charnes et al., 1978), still with the redistribution of inputs. Gomes \& Lins (2008), apply the uniformization of frontier techniques in the ZGS-DEA model to the distribution of an undesirable output, modelled as an input, in a case of environmental interest.

In radial projection cases, the uniformization does not represent major problems given that theorems already exist, which guarantee the methods in use - as stated in the articles mentioned hereabove. In case there are any restrictions in relation to weight, the success of the uniformization will depend on the validity of a conjecture formulated by Gomes (2003). Although it has not yet been demonstrated, this conjecture has been valid in previous case studies.

However, if there are any variables in the model that cannot be altered by the manager (non-controlled variables), the situation becomes more complex. This article shows (numerically) that the methods of uniformization previously used may not work in this case. A justification is also outlined as to why it does not work. A method of successive approximations is used in the case study presented, which, apparently, converges towards the final distribution with all the DMUs having unitary efficiency. In this article, the study is 
only conducted in an empirical form, not concerning itself with the theoretical foundations of the method for the moment.

The result of the approach developed here is applied to a case of establishing fee criteria at airports. The modelling of this problem requires ZSG-DEA models with weights restrictions and non-controlled variables. Given the lack of data, due to the natural state of secrecy of commercial airliners, a simulation was made in order to exemplify the problem. This simulation makes use of fictitious companies and is based on the average values of real companies from a few years back, so as to avoid confusion between our results and the real values of airline companies.

\section{Zero Sum Gains DEA Models}

\subsection{General Concepts and Radial Projections}

The classic DEA models, both the CCR model and the BCC model, in all their variants, assume total freedom of production. This means that the production of one DMU does not interfere with the production of the others. However, in some cases this freedom does not exist. In the case of competition, for example, if one considers as output the final result or an index that aggregates its results (Lins et al., 2003; Villa \& Lozano, 2004), a gain of position for any competitor implies a loss of position for one or more of its adversaries.

To deal with this type of situation, the so-called Zero Sum Gains DEA models (ZSG-DEA) were proposed. These represent a situation similar to that of a zero sum game, in which all that is gained by one player is lost by the other(s) (Gomes, 2003; Gomes et al., 2003, 2004, 2005; Lins et al., 2003; Gomes \& Lins, 2008). In other words, the net sum of gains must be zero. In contrast to what occurs in traditional models, the way in which a DMU reaches its target on the frontier can result in the alteration of the shape of the efficient frontier. In Lins et al. (2003) the authors propose strategies for the radial search of targets, highlighting the proportional reduction strategy. Applications of the ZSG-DEA model, other than those presented in the previously cited articles, can be seen in Gomes et al. $(2007,2008)$, Gomes \& Soares Mello (2009), Hu \& Fang (2010).

In the proportional strategy, the DMU that seeks efficiency (seeks the frontier) needs to gain certain units of output (or lose input). So that the sum remains constant, other DMUs must lose (or gain) in proportion to their levels of output (input). In this way, whichever has the lowest level of output (input) loses (gains) less; whichever has the highest level of output (input) loses (gains) more.

It may occur that more than one DMU will seek to maximise efficiency, which can be done in competition or cooperation. The most interesting case in ZSG modelling is that in which inefficient DMUs form a cooperation group. In the ZSG-DEA paradigm, the search for cooperation means that DMUs from this group try to allocate a certain amount of input (or to remove an amount of output) only to the DMUs that do not belong to this group.

In a general case of multiple inefficient DMUs operating in a cooperation regime, the ZSG-DEA model is a Multi-objective Nonlinear Programming Problem (Gomes et al., 2003). Problems of this type frequently lead to the use of metaheuristics. However, for the proportional reduction strategy the model is reduced to a Mono-objective Nonlinear Programming model, according to the Proportional Efficiencies in the Proportional Strategies Theorem (Gomes et al., 2005). Its statement establishes that in the problem of various DMUs

Pesquisa Operacional, v.30, n.1, p.175-193, Janeiro a Abril de 2010 
in cooperation in the search for targets with proportional strategy, the efficiencies of the DMUs in the ZSG-DEA model are directly proportional to their efficiencies in the classic DEA model.

In a case where all the inefficient DMUs form a single cooperation group and seek efficiency in the classic DEA efficiency frontier, the application of the ZSG-DEA model brings about the redistribution of input or of the constant sum output. After this redistribution, all DMUs will belong to the efficient frontier; in other words, all will be $100 \%$ efficient.

This new DEA frontier, referred to here as the uniform DEA frontier or maximum efficiency frontier, is located at lower levels than the those of the classic DEA model, as efficient DMUs gain input units (or lose output units) to compensate the loss (or gain) of inefficient units, so as to maintain a constant sum. This situation of uniform efficiency can be seen as desirable by regulatory agencies, since what will be presented to the decision-maker is a distribution of resources (or products) that makes all units 100\% efficient. This is the approach followed by Gomes \& Lins (2008).

In order to build a uniform frontier directly, in which inefficient DMUs form one single group of cooperation $W$, Gomes et al. (2003) demonstrated the Target Determination Theorem, which was used by Gomes \& Lins (2008). This theorem states that the target of the DMU under analysis in the ZSG-DEA model with proportional strategy is equal to the target in the classic case multiplied by the reduction coefficient. This theorem, together with the Proportional Efficiencies in the Proportional Strategies Theorem, allows us to reduce the solution to the Nonlinear Programming Problem to one single nonlinear equation. For the CCR and BCC models, with input orientation, we have equation (1), where $h_{R o}$ and $h_{o}$ are, respectively, the measurements of efficiency in the ZSG-DEA and classic DEA models for DMU $o$; $W$ is the group of DMUs $(j)$ in cooperation; $r_{o j}=h_{o-I} / h_{j-I}$ is the factor of proportionality resulting from employing the proportional strategy, with input orientation. Equation (2) is valid for output oriented models, in which $q_{o j}=h_{o-O} / h_{j-O}$ is the proportionality factor.

$$
\begin{aligned}
& h_{R o}=h_{o}\left(1+\frac{\sum_{j \in W}\left[x_{j}\left(1-r_{o j} h_{R o}\right)\right]}{\sum_{j \notin W} x_{j}}\right) \\
& h_{R o}=h_{o}\left(1-\frac{\sum_{j \in W}\left[y_{j}\left(q_{o j} h_{R o}-1\right)\right]}{\sum_{j \notin W} y_{j}}\right)
\end{aligned}
$$

\subsection{Non-Radial Projections}

The ZSG-DEA models presented so far impose the constant sum restriction only to the output or to the single input of the model, or to all of the outputs or inputs of constant sum. These are radial models, namely, they consider the proportional reduction or increase of inputs or of outputs, and do not assume simultaneous alterations.

It is interesting to note that there could be cases where an input (or output) of constant sum coexists with other inputs (outputs) of non-constant sum. In these multidimensional models, 
the projections are not radial, in other words, the variations of inputs and outputs are not proportional. There follows a description of how to treat ZSG-DEA in such a situation.

Take a ZSG-DEA problem modelled with $i=1 \ldots r$ inputs and $k=1 \ldots s$ outputs, in which only the output $f$ is of constant sum. The remaining variables are not restricted, as in the classic DEA models. For an output-oriented model, the zero sum gains 'game' will be valid only for the output $f$. As there will be no redistribution or relocation of the other outputs present in the model, these can be assumed as analogous to the non-controllable variables (Cooper et al., 2000).

Equation (3) presents the non-radial CCR ZSG-DEA model, output oriented, in which the efficiency is measured only by the alteration of one of the outputs (namely, of which a constant sum is imposed). In this model $h_{R o}$ is the inverse of the efficiency of the DMU $o$; $x_{j i}$ and $y_{j k}$ are the values of inputs $i$ and outputs $k$ of the DMUs $j$, respectively; $\lambda_{j}$ represents the contribution of the DMUs $j$ in the composition of the target of DMU $o ; y^{\prime}{ }_{j f}$ represents the new values of output $f$ after reallocation.

Non-radial BCC ZSG-DEA models are analogous, with one exception: the addition of the convexity constraint $\sum_{j} \lambda_{j}=1$.

$$
\begin{aligned}
& \operatorname{Max} h_{R o} \\
& \text { subject to } \\
& x_{i} \geq \sum_{j} \lambda_{j} x_{j i}, \forall i \\
& h_{R o} y_{o f} \leq \sum_{j} \lambda_{j} y^{\prime}{ }_{j f} \\
& y_{k} \leq \sum_{j} \lambda_{j} y_{j k}, \forall k \neq f \\
& \lambda_{j} \geq 0, \forall j
\end{aligned}
$$

\subsection{Weights Restrictions}

The classic DEA models allow for total freedom in the choice of weights that will give the maximum efficiency value to a given DMU. This freedom is important in the identification of inefficient units, in other words, of those DMUs that present a poor performance including with their own set of multipliers.

The flexibility in the choice of weights is one of the advantages appointed to DEA modelling. Nevertheless, the calculated weights can be inconsistent with the knowledge in relation to the relative values of inputs and outputs, what can generate the need to introduce additional constraints.

When there are preferences between inputs and/or outputs among the decision agents, these value judgements are incorporated into the DEA models by means of restrictions to the weights (or multipliers) associated with inputs and/or outputs of the assessed units. Allen et al. (1997) and Thanassoulis et al. (2004), present a survey on the evolution of value judgements incorporation through weights restrictions. Lins et al. (2007) show how impracticalities arise and how to avoid them in the DEA LPPs that incorporate weights 
restrictions. Joro \& Viitala (2004) study the relationship between weights restrictions and specialist opinions. Podinovski (2005) analyses the role of limits to the weights in DEA. Halme et al. (1999) present an alternative proposal for incorporating preferences in DEA without the use of weights restrictions.

Angulo Meza \& Lins (2002) consider that the use of weights restrictions is one of the techniques that improve discrimination in DEA with decision-makers subjective opinions. Adler et al. (2002) also include weights restrictions within discrimination improvement techniques and present various types of restrictions. The main ones, according to Angulo Meza \& Lins (2002), are: (a) direct restrictions on multipliers; (b) input-output level adjustments observed for capturing value judgements; (c) restriction to virtual inputs and outputs.

Lins et al. (2003) present the radial ZSG-DEA model with weights restrictions, output oriented, with $k$ multiple outputs, all of constant sum. According to Gomes's (2003) conjecture, the Reference DMUs Contribution Equality Theorem and the Target Value Determination Theorem remain valid for the radial ZSG-DEA models with weights restrictions. This means that in the ZSG-DEA model with weights restrictions, as in the case without these restrictions, the values of the reference DMUs contributions are equal to those obtained from classic DEA models with weights restrictions, as long as the proportional reduction strategy is adopted. Consequently, the uniformization of the frontier can be achieved.

Nevertheless, as previously mentioned, there could be situations where only one of the outputs in the model must have constant sum and, furthermore, restrictions must be imposed to the output variables weights. In these cases, the corresponding model must be the nonradial ZSG-DEA with weights restrictions. This model (CCR, output oriented) is presented in (4), in which output $f$ is of constant sum and the remaining variables are not restricted. $A^{T} \gamma$ represents the coefficients matrix of the outputs weights restrictions, $A u \leq 0$. Analogous models can be derived for input orientation and the BCC situation.

$$
\begin{aligned}
& \operatorname{Max} h_{R o} \\
& \text { subject to } \\
& x_{i} \geq \sum_{j} \lambda_{j} x_{j i}, \forall i \\
& h_{R o} y_{o f} \leq \sum_{j} \lambda_{j} y^{\prime}{ }_{j f}-A^{T} \gamma_{i} \\
& y_{k} \leq \sum_{j} \lambda_{j} y_{j k}-A^{T} \gamma_{i}, \forall k \neq f \\
& \lambda_{j}, \gamma_{i} \geq 0, \forall j, i
\end{aligned}
$$

Through numeric experimentation, which will be shown in section 3 , it is verified that Gomes's conjecture (2003) does not remain valid for non-radial ZSG-DEA models with weights restrictions. This means that the uniformization of the efficient frontier is not reached in one round. Therefore, this conjecture cannot be generalised onto non-radial models with weights restrictions. Through numeric examples with two outputs, where one is of constant sum, it is observed that when the weights restriction imposed favours the constant sum output, the efficiency values were the same as those obtained with the non-radial model without weights restrictions. In this situation, uniformization is promptly obtained. However, when the imposed weights restriction favours the output of non-restricted sum, uniformization is only reached after following redistribution iterations of the constant sum output. 


\section{Case Study}

\subsection{Air Transport and Fees}

Air transport is responsible for a large part of domestic (in countries of great size like Brazil) and international travel. According to Ashford et al. (1991), the airport is an essential part of the tourist transport system, because it is the physical location where a transfer is made: from air transport to land and sea transport. One must also observe that, as stated by Martin-Cejas (2006), "the quality of the journey begins at the airport".

In 2000, the Brazilian Airport Infrastructure Company (Infraero) adopted the vision that airports represent much more than simply the air entrance to cities. They must be seen as essential elements in the economic development of the urban regions where they are installed and in the development of tourism (Palhares, 2001). Non-aeronautical revenue is becoming increasingly important to the revenue of airports, so that these do not become overly dependent on strictly aeronautical fees. A study of non-aeronautical revenues in the efficiency of airports can be seen in Soares de Mello \& Gomes (2004).

The importance of airline companies in generating non-aeronautical revenue for airports is clear. The more passengers are transported, the more revenue will be generated in services. This is because the consumption of products that are commercialised inside the airport tends to increase with the larger movement of passengers and their companions. In this way, airline companies contribute directly to greater returns in non-aeronautical revenue.

We propose here a fee discount concession model to airline companies as an incentive to increase the occupation of their airplanes and a stimulus to increase the number of passengers and visitors at airports. As a consequence, there would be an increase in non-aeronautical revenue, with a tendency to bring the airport closer to a self-sustainable operation. Aligned with this proposition, the more passengers an airline company brings to the airports, the larger the discount it will have on airport landing and ground stay fees. However, the discounts given to the 'more efficient' companies in terms of passenger transportation should be compensated with a type of surcharge on the companies with a smaller number of transported passengers. In this way, there is a need for both the discount and the surcharge to be calculated for each flight individually. For this purpose, the non-radial Zero Sum Gains DEA models based on the original proposal of ZSG-DEA, as discussed in Lins et al. (2003), Gomes et al. (2003, 2004, 2005) and Gomes \& Lins (2008) are proposed and presented. For a presentation of the main airport fees see Fonseca et al. (2004).

Some work has already been done in the field of air transport in respect of the use of the DEA model to evaluate airports. Without any pretence to an exhaustive list, some of these works are mentioned herebellow.

Gillen \& Lall (1997) recommend the use of DEA in these cases due to its non-parametric characteristics and due to the fact that DEA takes into account different factors simultaneously, although not including operational costs and revenues. Pels et al. (2001) compare European airports using DEA modelling. Adler \& Berechman (2001) use DEA to evaluate the quality of airports from the point of view of airline companies, with the intention of determining which airports companies should choose for hubs. Fernandes \& Pacheco (2002) use DEA to measure the efficiency of 35 Brazilian airports and, by doing so, evaluate their financial management and their infrastructures level of use. Pacheco \&

Pesquisa Operacional, v.30, n.1, p.175-193, Janeiro a Abril de 2010 
Fernandes (2003) use DEA to study the same 35 airports so that, under financial aspects and physical dimensions, they can identify means of improving performance. Pestana \& Dieke (2007) use DEA to evaluate Italian Airports.

\subsection{Modelling}

The new concept of attributing discounts in proportion to the quantity of passengers airline companies transport to each airport can be modelled through ZSG-DEA. In this paper, one airport will be analysed and the occupation rate of each flight at a given time on a weekday will be considered. Initially, according to the model proposed here, the discounts and surcharges, for each flight, focus only on the landing fee, so as to guarantee that the Infraero airport- related income remains constant in the airport under study. For this airport a model is applied where the DMUs are the flights operated in one day.

The model used is the non-radial CCR ZSG-DEA, output oriented. In this model, from the point of view of the airport administrator, the inputs are the maximum take-off weight (MTOW) of the aircraft, contained in its navigation certificate and measured in tons, and the duration of ground stay of the aircraft at the airport. The outputs are the non-airport-related revenue generated by the flight and the total fee paid.

The MTOW input indicates the maximum take-off weight of the aircraft. Generally, the greater this value, the larger the size of the aircraft and the greater the number of seats it offers. This implies that a larger number of passengers can be transported, which contributes to a greater collection of non-aeronautical related revenue by the airport's administration in its dependencies. As the landing and ground stay fee values depend on the MTOW of the aircraft, the greater the MTOW, the greater the amount charged by the airport for an aircraft to land. The amount charged by the hour for the aircraft to remain in the manoeuvre locations is also greater.

The input, length of stay of the aircraft in the manoeuvre location, measures the time spent by the aircraft in the manoeuvre location of the airport between flights. As in the point of view of the airline company 'aircraft on the ground make a loss', this variable measures the capacity of the airline company to prepare the aircraft for a new flight. The boarding and disembarking of passengers, the cleaning of the aircraft, the loading and unloading of luggage, and refuelling are some of the activities carried out by the company's team while the aircraft is on the ground. The shorter this time, the better the possibility that this aircraft will make more flights, and consequently, transport more passengers, bringing them to airports and therefore, increasing the collection of non-airport-related revenue. From the airport point of view this variable measures the unavailability of this space, which could be used by another aircraft. In other words, the shorter this time, the greater the possibility that more aircrafts will use this space and bring more passengers to the airport.

The output, non-aeronautical-related revenue generated by the flight, is virtually impossible to measure directly. Therefore, to substitute it, the number of passengers effectively transported was used, because it maintains a causal relationship with the non-aeronautical income.

Total paid fee corresponds to the landing fee plus the ground stay fee. The ground stay fee is only charged to the airline company in the case of its aircraft exceeding the first three hours of parking after landing. Thus, the greater the number of hours parked, the greater the amount that will be charged to the company. 
The model proposed here fits into a total reformulation of fees and has the objective of measuring the efficiency of each flight in generating non-aeronautical revenue for the airports. Based on this efficiency, discounts and surcharges are attributed to the value of the total fee (landing and ground stay), so that the amount collected by the airport administration remains constant.

The constant sum output is, therefore, the total landing fee, in other words, after the execution of the model there will be an increase of output to the least efficient flights and a decrease of output to the most efficient flights, maintaining the total of this variable unchanged. Besides verifying which flights were most efficient in generating revenue for the airport administration, it is necessary to identify how much should really have been paid and, thus obtain the discount or surcharge. For this, a new value was calculated for the total landing fee output, for all DMUs (flights) in such a way that, with this new value, all are efficient.

The DMUs analysed in the model are domestic flights operated at a given airport. As there is difficulty obtaining real data, the data here was simulated. The difficulty in accessing trustworthy data about air transport has already been mentioned, for example, in Soares de Mello et al. (2005).

A total of 26 flights were considered spread through three different fictitious companies, $\mathrm{C} 1, \mathrm{C} 2, \mathrm{C} 3$. We supposed that all companies were of similar size, one of them being slightly larger than the other two. In this way, 13 flights were considered for company $\mathrm{C} 1,13$ for company $\mathrm{C} 2$ and 10 flights for company $\mathrm{C} 3$.

Some aircraft were chosen, from among the ones that operate within the Brazilian air network (and which, therefore, had easily available data) to make up the fleet of these fictitious companies. This fleet is presented in Table 1, where the MTOW and the number of seats of each aircraft for each airline company appear.

Table 1 - Aircraft, MTOW and seats.

\begin{tabular}{|c|c|c|c|}
\hline & Aircraft & MTOW (in tons) & Number of seats \\
\hline \multirow{5}{*}{$\mathrm{C} 1$} & $767-300$ & 181 & 196 \\
\hline & $737-800$ & 77 & 156 \\
\hline & $737-700$ & 68 & 132 \\
\hline & $737-500$ & 52 & 117 \\
\hline & $737-300$ & 61 & 132 \\
\hline \multirow{3}{*}{$\mathrm{C} 2$} & A-320 & 70 & 162 \\
\hline & A-319 & 64 & 132 \\
\hline & Fokker 100 & 44 & 108 \\
\hline \multirow{2}{*}{ C3 } & $737-700$ & 62 & 144 \\
\hline & $737-800$ & 62 & 177 \\
\hline
\end{tabular}

\subsection{Data}

The data used in the model is simulated, because it was not possible to obtain real data. Firstly, it is necessary to know which airliners operate the flights of which company. For this, one considers the aircraft in Table 2 as each company's fleet. This table shows the aircraft classified by type, quantity of each aircraft in the fleet $(\mathrm{N})$ and the probability of each 
aircraft operating a flight (Prob). The probability of each aircraft operating a flight is given by the ratio between the number of aircraft of each type and the total number of aircraft from each company.

Table 2 - Probability of each aircraft in the fleet of airline companies.

\begin{tabular}{|c|c|c|c|c|c|c|c|c|}
\hline \multicolumn{3}{|c|}{ C1 } & \multicolumn{3}{|c|}{$\mathrm{C2}$} & \multicolumn{3}{|c|}{ C3 } \\
\hline Aircrafts & $\mathbf{N}$ & Prob & Aircraft & $\mathbf{N}$ & Prob & Aircraft & $\mathbf{N}$ & Prob \\
\hline $767-300$ & 8 & 0,1356 & A-320 & 31 & 0,4769 & $737-700$ & 21 & 0,8750 \\
\hline $737-800$ & 2 & 0,0339 & A-319 & 13 & 0,2000 & $737-800$ & 3 & 0,1250 \\
\hline $737-700$ & 3 & 0,0508 & Fokker 100 & 21 & 0,3230 & & & \\
\hline $737-500$ & 14 & 0,2373 & & & & & & \\
\hline $737-300$ & 32 & 0,5423 & & & & & & \\
\hline
\end{tabular}

A discreet distribution is carried out with this data, where the discreet variables are the aircraft types. The probability of each aircraft operating a flight is also inserted. This is performed for each airline company, in other words, for company $\mathrm{C} 1$ five discreet variables are considered with their respective probabilities and 13 random numbers are generated. For $\mathrm{C} 2$ three discreet variables are considered and 13 random numbers are also generated. For C3 two discreet variables are considered and 10 random numbers generated.

To obtain the number of passengers transported it is necessary to generate values for the occupation of flights. These values are obtained by a triangular distribution, where the values for the averages are the ones available on the website of the former Civil Aviation Department. For each fictitious company the average data of each of three real companies was used. The calculation of the effective number of passengers transported is given by the 'occupation of each flight' multiplied by the 'number of seats available in the aircraft that operates the flight'.

As the landing and ground stay fees depend on the MTOW of the aircraft, the values for the total paid fee are obtained at Portaria N. ${ }^{\circ} 33 /$ DGAC. According to the Portaria $\mathrm{N} .^{\circ} 440 / \mathrm{SOP}$, the standard MTOW for aircraft classified in group I, for the charging of use of services supplied by the aeronautical infrastructure, is calculated based on the weighted average of the fleet of each company, by type of aircraft. The individual MTOW of each aircraft is considered for the purposes of charging landing and ground stay fees. This is justified by the fact that airline companies with a larger number of smaller sized aircrafts benefit from the value of these fees. In addition, it is because the standard MTOW does not make sense, as the discounts will be given by flight to the airline company. The values charged by category I airports are considered for the landing and ground stay fees.

The data for the ground stay of each aircraft after landing is also simulated through empirical observation.

The values of each variable for each DMU are found in Table 3. The value of the sum of the total fee referring to all the flights corresponds to $\mathrm{R} \$ 4,457.27$. It must be stressed that this value is apparently small. However, 36 flights is a number that only corresponds to a small period of time in the daily operation of a busy airport, like Guarulhos and Congonhas, in São Paulo, and Santos Dumont and Galeão, in Rio de Janeiro. On adding up the values throughout a period of 30 days and considering all the flights of a same company in major 
airports in the country, the value of the fees becomes quite significant. According to the values of the case study presented here, each airline company fictitiously pays the following values for the flights they operate: $\mathrm{C} 1=\mathrm{R} \$ 1,870.29 ; \mathrm{C} 2=\mathrm{R} \$ 1,469.74 ; \mathrm{C} 3=\mathrm{R} \$ 1,117.24$.

Table 3 - Model data.

\begin{tabular}{|c|c|c|c|c|c|c|}
\hline Company & Aircraft & DMUs & MTOW & $\begin{array}{c}\text { Duration of } \\
\text { ground stay (min) }\end{array}$ & $\begin{array}{l}\text { Passengers } \\
\text { transported }\end{array}$ & $\begin{array}{c}\text { Total fee } \\
\text { (R\$) }\end{array}$ \\
\hline \multirow{13}{*}{$\mathrm{C} 1$} & $737-300$ & DMU 1 & 61 & 50 & 68 & 101.87 \\
\hline & $737-800$ & DMU 2 & 77 & 40 & 119 & 128.59 \\
\hline & $737-700$ & DMU 3 & 68 & 40 & 100 & 113.56 \\
\hline & $737-500$ & DMU 4 & 52 & 240 & 87 & 155.48 \\
\hline & $737-500$ & DMU 5 & 52 & 60 & 85 & 86.84 \\
\hline & $737-500$ & DMU 6 & 52 & 70 & 61 & 86.84 \\
\hline & $737-300$ & DMU 7 & 61 & 30 & 67 & 101.87 \\
\hline & $737-300$ & DMU 8 & 61 & 40 & 58 & 101.87 \\
\hline & $737-300$ & DMU 9 & 61 & 50 & 69 & 101.87 \\
\hline & $737-500$ & DMU 10 & 52 & 40 & 67 & 86.84 \\
\hline & $737-300$ & DMU 11 & 61 & 40 & 126 & 101.87 \\
\hline & $767-300$ & DMU 12 & 181 & 300 & 138 & 600.92 \\
\hline & $737-300$ & DMU 13 & 61 & 50 & 95 & 101.87 \\
\hline \multirow{13}{*}{$\mathrm{C} 2$} & F-100 & DMU 14 & 44 & 40 & 68 & 73.48 \\
\hline & A-320 & DMU 15 & 70 & 50 & 88 & 116.90 \\
\hline & A-319 & DMU 16 & 64 & 240 & 105 & 191.36 \\
\hline & A-320 & DMU 17 & 70 & 70 & 74 & 116.90 \\
\hline & A-320 & DMU 18 & 70 & 50 & 125 & 116.90 \\
\hline & A-320 & DMU 19 & 70 & 50 & 110 & 116.90 \\
\hline & A-320 & DMU 20 & 70 & 40 & 131 & 116.90 \\
\hline & F-100 & DMU 21 & 44 & 40 & 66 & 73.48 \\
\hline & A-319 & DMU 22 & 64 & 30 & 101 & 106.88 \\
\hline & A-319 & DMU 23 & 64 & 50 & 74 & 106.88 \\
\hline & F-100 & DMU 24 & 44 & 40 & 70 & 73.48 \\
\hline & F-100 & DMU 25 & 44 & 40 & 58 & 73.48 \\
\hline & A-320 & DMU 26 & 70 & 180 & 96 & 186.20 \\
\hline \multirow{10}{*}{$\mathrm{C} 3$} & $737-700$ & DMU 27 & 62 & 40 & 109 & 103.54 \\
\hline & $737-800$ & DMU 28 & 62 & 240 & 125 & 185.38 \\
\hline & $737-700$ & DMU 29 & 62 & 70 & 127 & 103.54 \\
\hline & $737-700$ & DMU 30 & 62 & 40 & 124 & 103.54 \\
\hline & $737-700$ & DMU 31 & 62 & 50 & 115 & 103.54 \\
\hline & $737-700$ & DMU 32 & 62 & 30 & 43 & 103.54 \\
\hline & $737-700$ & DMU 33 & 62 & 30 & 127 & 103.54 \\
\hline & $737-800$ & DMU 34 & 62 & 50 & 146 & 103.54 \\
\hline & $737-700$ & DMU 35 & 62 & 40 & 101 & 103.54 \\
\hline & $737-700$ & DMU 36 & 62 & 30 & 108 & 103.54 \\
\hline
\end{tabular}




\section{Results and Discussion}

The non-radial ZSG-DEA CCR model, oriented to outputs, with weights restrictions is calculated. It is desired that the output number of passengers transported has a greater weight than the output total fee. However, as the two variables are measured in different units, the previous statement, by itself, is meaningless (Allen et al., 1997; Gomes et al., 2009a). For it to make sense, it would be necessary to normalise the data, which would bring problems of interpreting the results of the redistribution of the total fee output. Thus, the option was made to perform a normalisation by the sum, incorporated not to the data, but to the weights restriction of these variables. In this way, the restriction added is $u_{1}-1,2991 u_{2} \geq 0$. This value corresponds to the ratio between the sum of the values of the total fee of all the DMUs and the sum of the values of passengers transported by all of the DMUs.

The first step is to run the non-radial model with weights restrictions so as to obtain the efficient measurements of each DMU. To obtain the uniformised frontier, the DMUs targets for the variable of constant sum, total fee, are determined. The values of the efficiency measurements and the targets are found in Table 4.

It was confirmed that the DMUs 28,33 and 34 are efficient by the non-radial model. The DMUs 16, 26 and 28 present high values of efficiency, even though they possess high ground stay times. This is because a large aircraft operates them. They also have a reasonably high rate of occupation and, consequently, they transported a number of passengers greater than the average. They also have an increased total fee value due to the ground stay fee, even with the use of weights restrictions. These factors mean that these flights have relatively high efficiency values.

After that, the proportional reduction strategy is applied to the target output and, in this way, new values for the total fee for each DMU are obtained, according to Table 4.

The next step is to run the model again with the new output values obtained. It was expected, according to the conjecture of Gomes (2003) for radial ZSG-DEA models with weights restrictions, to achieve uniformization, in other words, all the DMUs should be efficient. However, this was not observed. An average efficiency of $90.1 \%$ was obtained. As observed previously, in non-radial ZSG-DEA CCR models with weights restrictions, uniformization is not reached at first. It is necessary to perform repeated iterations, in order to calculate various redistributions of the output. In this way, the average efficiency improves at each iteration until uniformization is reached. The average efficiencies of the subsequent iterations were: $95.6 \%, 98.0 \%, 99.1 \%, 99.6 \%$ and $99.8 \%$. These average efficiencies, which are increasing, suggest that the method converges. It can be said, therefore, that the uniformization of the frontier is reached according to this approximate method. The result of the fifth (and last) iteration is shown in Table 5. In this table, the values of the final efficiency measurements and the final values of the total fee output for each DMU are presented. 
Table 4 - Values of each DMU efficiencies and their targets before and after the redistribution.

\begin{tabular}{|c|c|c|c|c|}
\hline Company & DMUs & $\begin{array}{c}\text { Non-radial } \\
\text { efficiency }\end{array}$ & $\begin{array}{l}\text { Target before } \\
\text { redistribution }\end{array}$ & $\begin{array}{c}\text { Target after } \\
\text { redistribution }\end{array}$ \\
\hline \multirow{13}{*}{$\mathrm{C} 1$} & DMU 1 & 0.5084 & 200.3737 & 138.7840 \\
\hline & DMU 2 & 0.7054 & 182.2937 & 126.2614 \\
\hline & DMU 3 & 0.6550 & 173.3740 & 120.0833 \\
\hline & DMU 4 & 0.8702 & 178.6716 & 123.7525 \\
\hline & DMU 5 & 0.6173 & 140.6771 & 97.4366 \\
\hline & DMU 6 & 0.4969 & 174.7635 & 121.0457 \\
\hline & DMU 7 & 0.5730 & 177.7836 & 123.1375 \\
\hline & DMU 8 & 0.5048 & 201.8027 & 139.7738 \\
\hline & DMU 9 & 0.5117 & 199.0815 & 137.8890 \\
\hline & DMU 10 & 0.5549 & 156.4967 & 108.3936 \\
\hline & DMU 11 & 0.8979 & 113.4536 & 78.5809 \\
\hline & DMU 12 & 0.8335 & 720.9598 & 499.3554 \\
\hline & DMU 13 & 0.6162 & 165.3197 & 114.5047 \\
\hline \multirow{13}{*}{$\mathrm{C} 2$} & DMU 14 & 0.6070 & 121.0544 & 83.8454 \\
\hline & DMU 15 & 0.5599 & 208.7873 & 144.6115 \\
\hline & DMU 16 & 0.8684 & 220.3593 & 152.6265 \\
\hline & DMU 17 & 0.4895 & 238.8151 & 165.4095 \\
\hline & DMU 18 & 0.7274 & 160.7094 & 111.3115 \\
\hline & DMU 19 & 0.6487 & 180.2066 & 124.8157 \\
\hline & DMU 20 & 0.8316 & 140.5724 & 97.3641 \\
\hline & DMU 21 & 0.5943 & 123.6413 & 85.6371 \\
\hline & DMU 22 & 0.7783 & 137.3249 & 95.1148 \\
\hline & DMU 23 & 0.5225 & 204.5550 & 141.6801 \\
\hline & DMU 24 & 0.6203 & 118.4588 & 82.0476 \\
\hline & DMU 25 & 0.5482 & 134.0387 & 92.8386 \\
\hline & DMU 26 & 0.7700 & 241.8182 & 167.4895 \\
\hline \multirow{11}{*}{$\mathrm{C} 3$} & DMU 27 & 0.7434 & 139.2790 & 96.4682 \\
\hline & DMU 28 & 1.0000 & 185.3800 & 128.3990 \\
\hline & DMU 29 & 0.7728 & 133.9803 & 92.7982 \\
\hline & DMU 30 & 0.8644 & 119.7825 & 82.9645 \\
\hline & DMU 31 & 0.7199 & 143.8255 & 99.6173 \\
\hline & DMU 32 & 0.4868 & 212.6952 & 147.3182 \\
\hline & DMU 33 & 1.0000 & 103.5400 & 71.7145 \\
\hline & DMU 34 & 1.0000 & 103.5400 & 71.7145 \\
\hline & DMU 35 & 0.6918 & 149.6675 & 103.6636 \\
\hline & DMU 36 & 0.8074 & 128.2388 & 88.8215 \\
\hline & & & Total & $4,457.2700$ \\
\hline
\end{tabular}


Table 5 - Final result: efficiency and total fee.

\begin{tabular}{|c|c|c|c|}
\hline Company & DMUs & Efficiency & Total fee \\
\hline \multirow{13}{*}{$\mathrm{C} 1$} & DMU 1 & 0.9937 & 150.1055 \\
\hline & DMU 2 & 0.9958 & 123.1194 \\
\hline & DMU 3 & 0.9952 & 120.3897 \\
\hline & DMU 4 & 0.9980 & 109.5555 \\
\hline & DMU 5 & 0.9954 & 96.7640 \\
\hline & DMU 6 & 0.9943 & 127.2013 \\
\hline & DMU 7 & 0.9943 & 128.9365 \\
\hline & DMU 8 & 0.9937 & 151.5673 \\
\hline & DMU 9 & 0.9937 & 148.8821 \\
\hline & DMU 10 & 0.9941 & 114.5857 \\
\hline & DMU 11 & 0.9984 & 68.3838 \\
\hline & DMU 12 & 0.9937 & 539.7584 \\
\hline & DMU 13 & 0.9948 & 117.0767 \\
\hline \multirow{13}{*}{$\mathrm{C} 2$} & DMU 14 & 0.9949 & 85.5148 \\
\hline & DMU 15 & 0.9942 & 152.4620 \\
\hline & DMU 16 & 0.9977 & 136.5431 \\
\hline & DMU 17 & 0.9937 & 178.5468 \\
\hline & DMU 18 & 0.9961 & 107.2004 \\
\hline & DMU 19 & 0.9951 & 125.5497 \\
\hline & DMU 20 & 0.9974 & 88.2394 \\
\hline & DMU 21 & 0.9947 & 87.9614 \\
\hline & DMU 22 & 0.9964 & 90.2306 \\
\hline & DMU 23 & 0.9938 & 152.2733 \\
\hline & DMU 24 & 0.9950 & 83.0682 \\
\hline & DMU 25 & 0.9942 & 97.7476 \\
\hline & DMU 26 & 0.9958 & 163.4978 \\
\hline \multirow{11}{*}{$\mathrm{C} 3$} & DMU 27 & 0.9963 & 92.0654 \\
\hline & DMU 28 & 1.0000 & 104.6054 \\
\hline & DMU 29 & 0.9975 & 83.8245 \\
\hline & DMU 30 & 0.9979 & 73.7162 \\
\hline & DMU 31 & 0.9960 & 96.3470 \\
\hline & DMU 32 & 0.9935 & 161.1811 \\
\hline & DMU 33 & 1.0000 & 58.4251 \\
\hline & DMU 34 & 1.0000 & 58.4251 \\
\hline & DMU 35 & 0.9956 & 101.8517 \\
\hline & DMU 36 & 0.9971 & 81.6675 \\
\hline & & Total fee paid & $4,457.2700$ \\
\hline
\end{tabular}


Using this final result, a calculation is made of how much each airline company, fictitiously should pay after the redistribution of the total fees values in each flight: $\mathrm{C} 1=\mathrm{R} \$ 1,996.36$; $\mathrm{C} 2=\mathrm{R} \$ 1,548.84 ; \mathrm{C} 3=\mathrm{R} \$ 912.11$.

It was confirmed that the total value to be paid by company $\mathrm{C} 1$ for the flights analysed here would be $6.7 \%$ greater. Company $\mathrm{C} 2$ would pay an amount approximately $5.4 \%$ greater and C3 would receive a discount in the total value paid for its flights of approximately $18.4 \%$.

It was also noted that 18 flights would receive a discount and another 18 would have to pay a surcharge. The flights referring to the DMUs 8,17 and 32 would receive a greater percentage increase in their fees: $49 \%, 53 \%$ and $56 \%$, respectively. It was also observed that they are all flights that transport few passengers. However, the flights referring to the DMUs 28, 33 and 34 would receive a greater percentage discount in their fees: $44 \%$. These are flights that transport a greater number of passengers.

Airline company $\mathrm{C} 3$ would receive the most discounts in its flights, 9 flights with discounts; company $\mathrm{C} 2$ received discounts in 5 flights, and $\mathrm{C} 1$ in 4 flights. It was also observed that there was an average occupation of 0.57 for the flights that are surcharge. For the 18 flights that would obtain discounts, the average occupation is 0.78 .

\section{Conclusions}

This article dealt, solely in an empirical way, with an extension of the ZSG-DEA that considers simultaneous weights restrictions and non-controllable variables. This non-radial model does not permit the uniformization of the frontier by the method of clustering all the inefficient DMUs in a single group of cooperation. This shows that the extension of the Gomes (2003) conjecture is no longer valid for the present case. Nevertheless, previous numerical experiments, both with the conjecture and its extension for a non-radial model without weights restrictions, have been shown to be valid. Although it is still necessary to demonstrate the conjecture (which may, possibly, not be valid in the simple case for which it was stated), it is necessary to understand the reason why, when two simple situations are joined, it is no longer possible to use the target proportionality theorem and a single group of cooperation for the uniformization of the frontier. This study is left as a suggestion for future work.

Regarding the algorithm proposed here (successive iterations) there is also no guarantee that this will work in all cases. In the numerical experiments carried out, there was always apparent convergence, although it was not always fast. The properties of this algorithm, including its theoretical validation, should also be the subject of new research.

As regards the case study, the proposal to attribute discounts on the airline fees according to the number of passengers transported signifies a means by which the airport administrators encourage the airline companies to become more efficient, review their costs and, consequently, the price of the airline tickets. In this way, as well as encouraging competition between the airline companies, the concept presented here can result in a greater movement of passengers (and companions) in the airports which opt to use it. In turn, this greater movement will generate greater non-aeronautical revenue. For this to occur, it is necessary that the administrators of Brazilian airports fully realise the importance of this type of revenue as well as investment in shopping and leisure options, also in such a way as to attract diverse visitors. A small beginning of awareness of the non-aeronautical revenue fundamental importance can be notice by the increasing presence of AeroShoppings in the Brazilian Airport. 
American and European airports, most of them privatised and with a more commercial philosophy, have noticed the importance of the ever increasing non-aeronautical revenues. Privatisation, in turn, requires regulation of prices. Discussion over single till or dual till divides the opinions of air transport specialists and researchers. See for example, Czerny (2006). The model proposed here presents hybrid characteristics of dual till and single till.

\section{References}

(1) Adler, N.; Friedman L. \& Sinuany-Stern, Z. (2002). Review of ranking methods in the data envelopment analysis context. European Journal of Operational Research, 140(2), 249-265.

(2) Adler, N. \& Berechman, J. (2001). Measuring airport quality from the airlines' viewpoint: An application of data envelopment analysis. Transport Policy, 8(3), 171-181.

(3) Allen, R.; Athanassopoulos, A.; Dyson, R.G. \& Thanassoulis, E. (1997). Weights restrictions and value judgements in data envelopment analysis: evolution, development and future directions. Annals of Operations Research, 73, 13-34.

(4) Angulo Meza, L. \& Lins, M.P.E. (2002). Review of methods for increasing discrimination in data envelopment analysis. Annals of Operations Research, 116, 225-242.

(5) Ashford, H.; Stanton, H. \& Moore, C. (1991). Airport Operations. Pitman, London.

(6) Asmild, M.; Paradi, J.C. \& Pastor, J.T. (2009). Centralized resource allocation BCC models. Omega, 37(1), 40-49.

(7) Avellar, J.V.G.; Milioni, A.Z. \& Rabello, T.N. (2005). Modelos DEA com variáveis limitadas ou soma constante. Pesquisa Operacional, 25(1), 135-150.

(8) Avellar, J.V.G.; Milioni, A.Z. \& Rabello, T.N. (2007). Spherical frontier DEA model based on a constant sum of inputs. Journal of the Operational Research Society, 58(9), 1246-1251.

(9) Banker, R.D.; Charnes, A. \& Cooper, W.W. (1984). Some models for estimating technical scale inefficiencies in Data Envelopment Analysis. Management Science, 30(9), 1078-1092.

(10) Barr, R.S.; Durchholz, M.L. \& Seiford, L. (2000). Peeling the DEA onion: Layering and rank-ordering DMUs using tiered DEA. Technical Report, Southern Methodist University.

(11) Beasley, J.E. (2003). Allocating fixed costs and resources via data envelopment analysis. European Journal of Operational Research, 147(1), 198-216.

(12) Charnes, A.; Cooper, W.W. \& Rhodes, E. (1978). Measuring the Efficiency of Decision-Making Units. European Journal of Operational Research, 2(6), 429-444.

(13) Cooper, W.W.; Seiford, L.M. \& Tone, K. (2000). Discretionary, non-discretionary and categorical variables. In: Data envelopment analysis: a comprehensive text with models, applications and DEA-solver software [edited by W.W. Cooper, L.M. Seiford and K. Tone], Kluwer Academic Publishers, Boston, 183-219. 
(14) Czerny, A.I. (2006). Price-cap regulation of airports: Single-till versus dual-till. Journal of Regulatory Economics, 30(1), 85-97.

(15) Fang, L. \& Zhang, C.-Q. (2008). Resource allocation based on the DEA model. Journal of the Operational Research Society, 59(8), 1136-1141.

(16) Fernandes, E. \& Pacheco, R.R. (2002). Efficient use of airport capacity. Transportation Research Part A, 36(3), 225-238.

(17) Fonseca, A.B.M.; Soares de Mello, J.C.C.B. \& Espírito Santo Jr, R.A. (2004). Um estudo sobre tarifas aeroportuárias. Relatórios de Pesquisa em Engenharia de Produção, 4(15).

(18) Gillen, D. \& Lall, A. (1997). Developing measures of airport productivity and performance: an application of data envelopment analysis. Transportation Research Part E: Logistic and Transportation Review, 33(4), 261-273.

(19) Gomes, E.G. (2003). Modelos de Análise de Envoltória de Dados com Ganhos de Soma Zero. Tese (Doutorado em Engenharia de Produção) - COPPE, Universidade Federal do Rio de Janeiro. Rio de Janeiro.

(20) Gomes, E.G. \& Lins, M.P.E. (2008). Modelling undesirable outputs with zero sum gains data envelopment analysis models. Journal of the Operational Research Society, 59(5), 616-623.

(21) Gomes, E.G. \& Soares de Mello, J.C.C.B. (2009). Distribuição de bolsas de iniciação científica com algoritmo híbrido baseado em eficiências DEA. Pesquisa Operacional para o Desenvolvimento, 1(2), 169-177.

(22) Gomes, E.G.; Soares de Mello, J.C.C.B. \& Angulo Meza, L. (2008). Large discreet resource allocation: a hybrid approach based on DEA efficiency measurement. Pesquisa Operacional, 28(3), 597-608.

(23) Gomes, E.G.; Soares de Mello, J.C.C.B. \& Lins, M.P.E. (2003). Busca seqüencial de alvos intemediários em modelos DEA com soma de outputs constante. Investigação Operacional, 23(2), 163-178.

(24) Gomes, E.G.; Soares de Mello, J.C.C.B. \& Lins, M.P.E. (2004). Redistribuição de inputs e outputs em modelos de análise de envoltória de dados com ganhos de soma zero. Pesquisa Operacional, 24(2), 269-284.

(25) Gomes, E.G.; Soares de Mello, J.C.C.B. \& Lins, M.P.E. (2005). Uniformização da fronteira eficiente em modelos de análise de envoltória de dados com ganhos de soma zero e retornos constantes de escala. Pesquisa Operacional, 25(2), 261-277.

(26) Gomes, E.G.; Soares de Mello, J.C.C.B. \& Mangabeira, J.A.C. (2009a). Estudo da sustentabilidade agrícola em um município amazônico com análise envoltória de dados. Pesquisa Operacional, 29(1), 23-42.

(27) Gomes, E.G.; Soares de Mello, J.C.C.B.; Souza, G.S.; Angulo Meza, L. \& Mangabeira, J.A.C. (2009b). Efficiency and sustainability assessment for a group of farmers in the Brazilian Amazon. Annals of Operations Research, 169, 167-181.

(28) Gomes, E.G.; Souza, G.S.; Lima, S.M.V. \& Fonseca, C.E.L. (2007). Alocação de bolsas de iniciação científica às unidades da Embrapa com modelos de Análise Envoltória de Dados com Ganhos de Soma Zero. Engevista, 9(1), 14-21. 
(29) Guedes, E.C.C.; Freitas, G.M.; Avellar, J.V.G. \& Milioni, A.Z. (2009). On the allocation of new inputs and ouputs with DEA. Engevista, 11(1), 4-7.

(30) Hadi-Vencheh, A.; Foroughi, A.A. \& Soleimani-Damaneh, M. (2008). A DEA model for resource allocation. Economic Modelling, 25(5), 983-993.

(31) Halme, M.; Joro, T.; Korhonen, P.; Salo, S. \& Wallenius, J. (1999). A value efficiency approach to incorporating preference information in data envelopment analysis. Management Science, 45(1), 103-115.

(32) Hu, J-L. \& Fang, C-Y. (2010). Do market share and efficiency matter for each other? An application of the zero-sum gains data envelopment analysis. Journal of the Operational Research Society, 61(4), 647-657.

(33) Joro, T. \& Viitala, E.J. (2004). Weight-restricted DEA in action: from expert opinions to mathematical models. Journal of the Operational Research Society, 55(8), 814-821.

(34) Korhonen, P. \& Syrjänen, M. (2004). Resource allocation based on efficiency analysis. Management Science, 50(8), 1134-1144.

(35) Lins, M.P.E.; Gomes, E.G.; Soares de Mello, J.C.C.B. \& Soares de Mello, A.J.R. (2003). Olympic ranking based on a zero sum gains DEA model. European Journal of Operational Research, 148(2), 312-322.

(36) Lins, M.P.E.; Silva, A.C.M. \& Lovell, C.A.K. (2007). Avoiding infeasibility in DEA models with weight restrictions. European Journal of Operational Research, 181(2), 956-966.

(37) Lozano, S.N.; \& Villa, G. (2005). Centralized DEA models with the possibility of downsizing. Journal of the Operational Research Society, 56(4), 357-364.

(38) Lozano, S.N. \& Villa, G. (2004). Centralized resource allocation using data envelopment analysis. Journal of Productivity Analysis, 22(1-2), 43-161.

(39) Martin-Cejas, R.R. (2006). Tourism service quality begins at the airport. Tourism Management, 27(5), 874-877.

(40) Nacif, F.B.; Soares de Mello, J.C.C.B. \& Angulo Meza, L. (2009). Choosing weights in optimal solutions for DEA-BCC models by means of a n-dimensional smooth frontier. Pesquisa Operacional, 29(3), 623-642.

(41) Pacheco, R.R. \& Fernandes, E. (2003). Managerial efficiency of Brazilian airports. Transportation Research Part A: Policy and Practice, 37(8), 667-680.

(42) Palhares, G.L. (2001). Transporte aéreo e turismo: gerando desenvolvimento socioeconômico. Editora Aleph, São Paulo.

(43) Pels, E.; Nijkamp, P. \& Rietveld, P. (2001). Relative efficiency of European airports. Transport Policy, 8(3), 183-192.

(44) Pestana, C.B. \& Dieke, P.U.C. (2007). Performance evaluation of Italian airports: A data envelopment analysis. Journal of Air Transport Management, 13(4), 184-191.

(45) Podinovski, V. (2005). The explicit role of weight bounds in models of data envelopment analysis. Journal of the Operational Research Society, 56(12), 1408-1418. 
(46) Soares de Mello, J.C.C.B.; Lins, M.P.E. \& Gomes, E.G. (2002). Construction of a smoothed DEA frontier. Pesquisa Operacional, 22(2), 183-201.

(47) Soares de Mello, J.C.C.B. \& Gomes, E.G. (2004). Eficiências aeroportuárias: uma abordagem comparativa com análise de envoltória de dados. Revista de Economia e Administração, 3(1), 15-23.

(48) Soares de Mello, J.C.C.B.; Gomes, E.G.; Biondi Neto, L. \& Lins, M.P.E. (2004). Suavização da fronteira DEA: O caso BCC tridimensional. Investigação Operacional, 24(1), 89-107.

(49) Soares de Mello, J.C.C.B.; Gomes, E.G.; Gomes, L.F.A.M.; Biondi Neto, L. \& Angulo Meza, L. (2005). Avaliação do tamanho de aeroportos portugueses com relações multicritério de superação. Pesquisa Operacional, 25(3), 313-330.

(50) Soares de Mello, J.C.C.B.; Gomes, E.G.; Leta, F.R. \& Soares de Mello, M.H.C. (2006). Algoritmo de alocação de recursos discretos com análise de envoltória de dados. Pesquisa Operacional, 26(2), 225-239.

(51) Thanassoulis, E.; Portela, M.C.S. \& Allen, R. (2004). Incorporating value judgments in DEA. In: Handbook on data envelopment analysis [edited by W.W. Cooper, L.M. Seiford and J. Zhu], Kluwer Academic Publishers, Boston, 99-138.

(52) Villa, G. \& Lozano, S.A. (2004). Constant Sum of Outputs DEA model for Olympic Games target setting. In: 4th International Symposium on DEA. Proceedings of the 4th International Symposium on DEA, Aston University, US, p. 36.

(53) Yan, H.; Wei, Q. \& Hao, G. (2002). DEA models for resource reallocation and production input/output estimation. European Journal of Operational Research, 136(1), 19-31. 